\title{
Solid-State Microstructure of Poly(L-lactide) and L-Lactide/ meso-Lactide Random Copolymers by Atomic Force Microscopy (AFM)
}

\author{
Mantana Kanchanasopa, Evangelos Manias, and James Runt* \\ Department of Materials Science \& Engineering and Materials Research Institute, \\ The Pennsylvania State University, University Park, Pennsylvania 16802
}

Received March 5, 2003; Revised Manuscript Received June 3, 2003

\begin{abstract}
Tapping mode atomic force microscopy was used to investigate the lamellar morphology of poly(L-lactide) and two poly(L-lactide-co-meso-lactide) random copolymers containing 3\% and 6\% meso-lactide. Samples were isothermally crystallized at selected temperatures, and qualitative and quantitative analyses of lamellar structure were performed using height and phase images. This is the first study of the morphology of polylactide stereocopolymers using a real-space probe, and the important effects of scanning parameters on the acquired images are described. More open spherulites with an abundance of screw dislocations between edge-on lamellar stacks were observed in samples crystallized at higher temperatures. Mean lamellar thicknesses are lower for the random copolymers compared to PLLA, particularly at lower $\Delta T$, in agreement with the results of our previous small-angle X-ray scattering (SAXS) experiments. Mean lamellar thicknesses derived from the current real-space examination are in good agreement with those determined previously from SAXS. Internal surfaces-from microtomed specimens-were also studied to investigate the bulk crystal morphology. Although quantitative analysis was not feasible (for reasons discussed in the text), lamellar organization similar to that seen in the surface experiments is observed at high magnifications.
\end{abstract}

\section{Introduction}

Polylactides are well-known as hydrodegradable and biocompatible thermoplastics. They are of interest in medical applications such as wound closure, prosthetic implants, and controlled-release systems. In addition, this family of polymers has received considerable attention because the monomers can be obtained from renewable agricultural sources. Hydrolytic and enzymatic degradability of semicrystalline polylactides and their stereocopolymers have been extensively studied. ${ }^{1-3}$ Degradation rate is controlled by the degree of crystallinity and lamellar organization, and the introduction of a second stereoisomer into the polymer chain influences not only the morphology but also selectivity in enzymatic degradation. ${ }^{2,3}$ To improve control over degradability and other properties of crystalline polylactides, the effect of comonomer type and content on crystalline order and morphology needs to be established. The influence of nonisothermal and isothermal crystallization processes on crystallinity and microstructure has been investigated for poly(L-lactide) $[\mathrm{PLLA}],{ }^{4-6}$ L-lactide/meso-lactide random copolymers,${ }^{7-9}$ L-lactide/D-lactide copolymers, ${ }^{10}$ and polylactide blends. ${ }^{11,12}$

In our previous research on polylactide copolymers having relatively high L-lactide contents, ${ }^{9,10,13}$ crystallization kinetics, lamellar microstructure, and melting behavior of meso- and D-lactide copolymers (with mole fraction of L-lactide ranging from $\sim 1$ to 0.88 ) were investigated. At equivalent comono-

* To whom correspondence should be addressed. Tel: 1-814-863-2749. Fax: 1-814-865-2917. E-mail: runt@matse.psu.edu. mer content, bulk crystallinities and spherulitic growth rates of copolymers containing randomly placed D-lactide units were found to be lower than those of meso-lactide copolymers because of the larger size of the D-lactide stereodefect. Small-angle X-ray scattering (SAXS) experiments were used to characterize the lamellar microstructure as a function of comonomer type and content. Lamellar thickness is an important signature of whether defects are uniformly included or excluded from lamellae. At a particular isothermal crystallization temperature $\left(T_{\mathrm{c}}\right)$, mean lamellar thickness is expected to decrease if defects are largely excluded from lamellae but increase for the case of uniform defect inclusion (because of a reduction in degree of supercooling).$^{14}$ In our previous SAXS studies of both meso- and D-lactide copolymers, lamellar thicknesses were found to decrease significantly with increasing comonomer content. These and other experimental findings strongly suggest that the minority comonomers are substantially rejected from the lamellar crystals. However, determination of microstructural parameters from reciprocal-space SAXS data requires a model structure (e.g., "infinite" lamellae stacks), and there is a degree of skepticism regarding the transformation of SAXS data to 1D correlation or interface distribution functions. Although care was taken in the analyses in our earlier studies, independent confirmation of these earlier findings is of importance.

Detailed information about the lamellar structural units is necessary for a complete understanding of the relationship between solid-state structure and physical properties. However, studies of lamellar structure have been limited by the 
Table 1. Characteristics of PLLA and Poly(L-lactide-co-meso-lactide) Copolymers ${ }^{9}$

\begin{tabular}{lccccc}
\hline \multicolumn{1}{c}{ material } & $R(\%)$ & $M_{\mathrm{n}}$ & $M_{\mathrm{w}}$ & $T_{\mathrm{g}}\left({ }^{\circ} \mathrm{C}\right)^{a}$ & $T_{\mathrm{m}}{ }^{\circ}\left({ }^{\circ} \mathrm{C}\right)^{b}$ \\
\hline PLLA & 0.4 & 65500 & 127400 & 56 & 215 \\
3\% meso-lactide & 2.1 & 65800 & 122600 & 56 & 200 \\
$\quad \begin{array}{c}\text { copolymer } \\
\text { 6\% meso-lactide }\end{array}$ & 3.4 & 63900 & 119100 & 56 & 187 \\
$\quad$ copolymer & & & & & \\
\hline
\end{tabular}

a Glass transition temperature of quenched (fully amorphous) samples. ${ }^{b}$ Equilibrium melting point. ${ }^{9}$

availability of high-magnification experimental probes, which can directly image at the nanometer length scale. Because atomic force microscopy (AFM) has comparable spatial resolution to transmission electron microscopy (TEM) and no special sample preparation is required, this technique, particularly tapping mode AFM, has received considerable attention recently in the study of the lamellar morphology of semicrystalline polymers. Quantitative analysis of lamellar structure of the $\beta$ crystalline form of isotactic polypropylene, ${ }^{15}$ poly(ethylene terephthalate), ${ }^{16}$ and poly(ethylene oxide) $)^{17}$ using AFM has been reported. The investigation of the morphology of thin films $(\sim 100 \mathrm{~nm}$ thick $)$ and drawn fibers of PLLA have also been reported recently. ${ }^{18-20}$

In the current paper, we present the results of the first quantitative study of the lamellar microstructure of PLLA and two random L-lactide/meso-lactide copolymers using tapping mode AFM. Mean lamellar thickness and distribution, as they are influenced by comonomer content and $T_{\mathrm{c}}$, are characterized, and comparison is made between the results of the present work and those from our earlier SAXS experiments. ${ }^{9}$ Initial results of our experiments were reported previously in ref 21 .

\section{Experimental Section}

A. Materials and Sample Preparation. PLLA and L-lactide/meso-lactide copolymers (Table 1) were synthesized via ring-opening polymerization in a presence of tin(II) octanoate. ${ }^{9}$ Previous NMR studies have shown that these copolymers are essentially random. ${ }^{22}$ All polymers used in this study are rich in L-lactide (i.e., the $S$ stereochemical isomer of lactic acid) and are crystallizable. The molecular weights of the polymers were determined by gel permeation chromatography, using tetrahydrofuran as the mobile phase and polystyrene molecular weight fractions as calibration materials. $R$ stereochemical isomer content was determined by chiral liquid chromatography and reported in mole [or, equivalently, weight] percent. As-received polymers were dried at $80{ }^{\circ} \mathrm{C}$ for $24 \mathrm{~h}$ under vacuum and kept in a desiccator until used.

For consistency with our previous reports, lactide dimers are referred to by their prefixes L, D, and meso. When polymerized, L-lactide results in the placement of two $S$ stereoisomer repeating units in a chain. Likewise, D-lactide results in two successive $R$ stereoisomer units, while mesolactide results in the introduction of one $R$ and one $S$ unit. The relative compositions of D-, L-, and meso-lactide in the backbone have a profound effect on crystallization behavior and ultimate solid-state microstructure.
A $1 \%$ solution of the desired (co)polymer in chloroform was deposited on a glass cover slip, and the solvent was allowed to evaporate overnight at room temperature. Dried samples were melted at a temperature $30{ }^{\circ} \mathrm{C}$ above their nominal melting point for $3 \mathrm{~min}$ in a Mettler hot stage (model FP-82), then transferred to a second hot stage preset at the crystallization temperature $\left(T_{\mathrm{c}}\right)$, and isothermally crystallized for $t_{\mathrm{c}}$ min. Film thicknesses used in the study of surface morphology were $\leq 5 \mu \mathrm{m}$ (estimated by calculation).

B. Tapping Mode AFM. The morphologies of the free surfaces of the cast films were characterized using a Nanoscope III MultiMode AFM (Digital Instruments) in tapping mode. The free amplitude $\left(A_{0}\right)$ used in this study was between 15 and $30 \mathrm{~nm}$. Most samples were characterized using a set-point amplitude ratio $\left(r_{\mathrm{sp}}\right)$ between 0.7 and 0.5 . However, for PLLA crystallized at 120 and $126{ }^{\circ} \mathrm{C}$, the $3 \%$ meso-lactide copolymer crystallized at 114 and $120^{\circ} \mathrm{C}$, and the $6 \%$ meso-lactide copolymer crystallized at $114^{\circ} \mathrm{C}, r_{\mathrm{sp}}$ was $0.9-0.8$. $\left[r_{\mathrm{sp}}\right.$ is defined as the ratio of the cantilever's oscillating amplitude (in contact) to its freely oscillating amplitude (out of contact)]. Set-point amplitudes near 1.0 correspond to very light normal forces (soft tapping), and lower $r_{\mathrm{sp}}$ corresponds to higher tapping force. Acquisition of images less than $\sim 20 \times 20 \mu \mathrm{m}^{2}$ was carried out at 0.5 Hz. To obtain initial information on larger spatial regions, a higher scan rate of $1 \mathrm{~Hz}$ was occasionally used.

All samples were probed with noncontact silicon cantilevers having resonant frequencies ranging from 280 to 380 $\mathrm{kHz}$. Samples for imaging the bulk morphology (thickness $\sim 1 \mathrm{~mm}$, prepared by hot pressing) were isothermally crystallized, and then cross-sectioned with glass knives at room temperature and at $-25{ }^{\circ} \mathrm{C}$ (i.e., $\sim 85{ }^{\circ} \mathrm{C}$ below $T_{\mathrm{g}}$ ) using a Leica UCT ultramicrotome. The surface of the cross section was consecutively sectioned until a smooth surface (to the eye) was obtained. Only the cross-sectional surface of the sample block was studied further-the thin sections were discarded.

\section{Results and Discussion}

A. Overall Morphology. Crystal habits exhibiting sheaflike features are mostly observed on the surfaces of the polylactide polymers crystallized at moderate degrees of supercooling, $\Delta T$ (Figures 1 and 2). Figure $1 \mathrm{a}-\mathrm{h}$ is representative AFM phase images of PLLA crystallized isothermally at 120,132 , and $147{ }^{\circ} \mathrm{C}$ imaged at various magnifications. Images $\mathrm{b}$ and $\mathrm{d}$ in Figure 1 were acquired from the boxed areas of images a and $\mathrm{c}$ of Figure 1, respectively. Images $\mathrm{e}$ and $\mathrm{f}$ of Figure 1 are images of "spherulites" acquired from two different areas of the specimen crystallized at $147^{\circ} \mathrm{C}$. Higher magnification images of areas marked as $g$ and $h$ in Figure 1e are presented in Figure 1, parts $g$ and h, respectively. Lamellae seen in these images orient relative to the surface in different ways, that is, edge-on, flat-on, and at some angle to the surface.

Features in certain portions of Figure 1a (for example, as indicated by the arrow) represent flat-on views of lamellae, while in other areas lamellae are edge-on, or nearly so. Many lamellae are edge-on in Figure 1b, particularly in the lower 
(a)

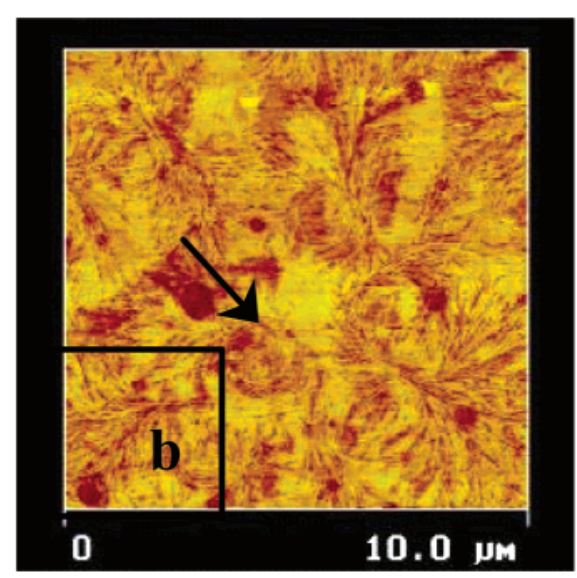

(c)

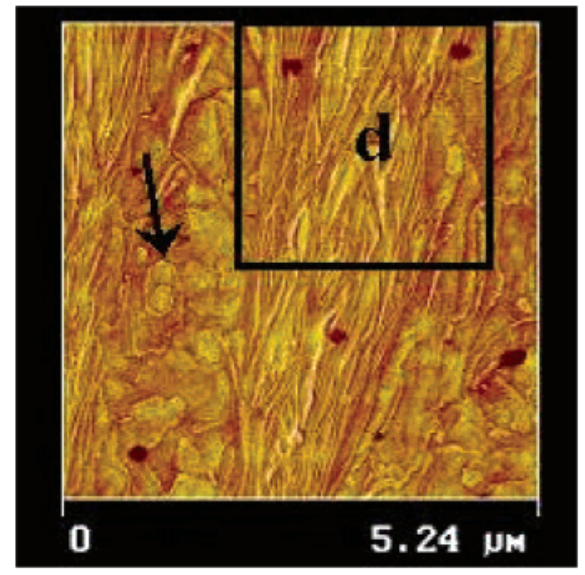

(e)

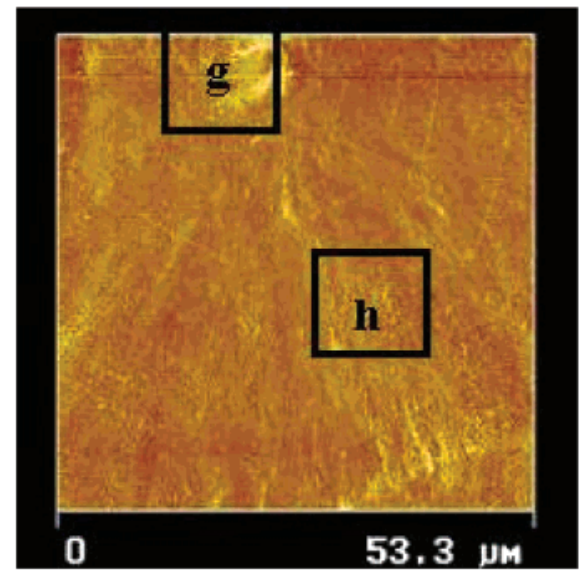

(g)

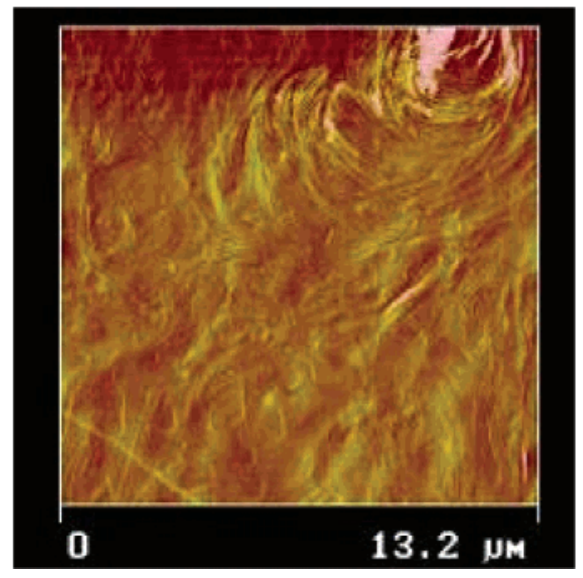

(b)

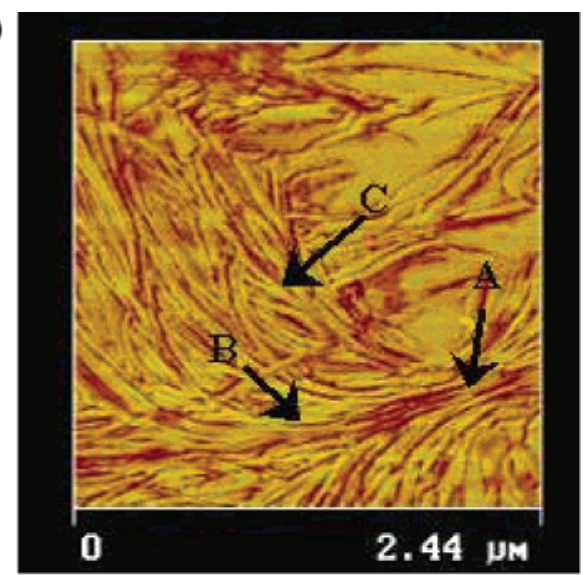

(d)

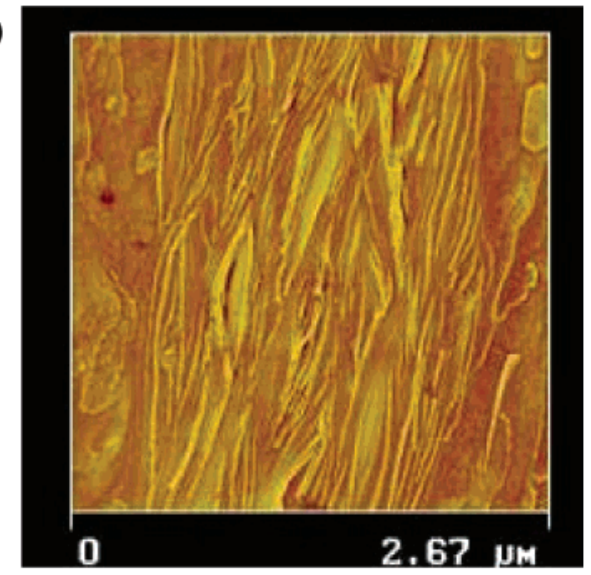

(f)

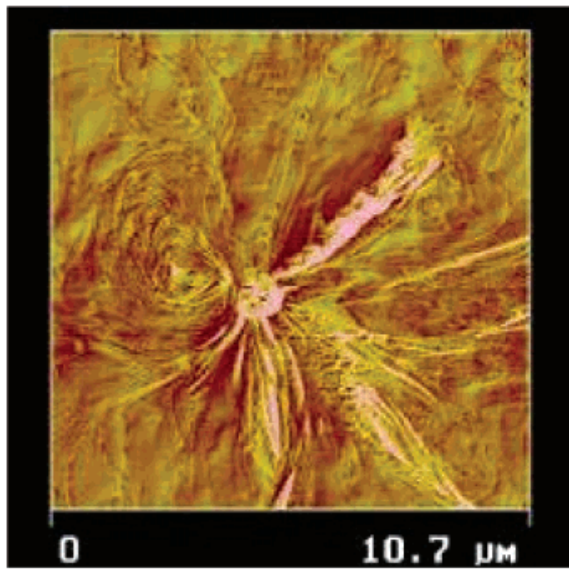

(h)

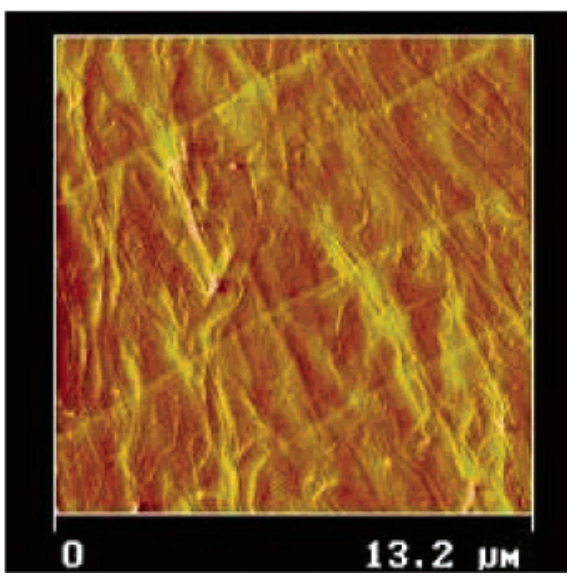

Figure 1. AFM phase images of PLLA isothermally crystallized at different temperatures: $(a, b)$ at $120{ }^{\circ} \mathrm{C}$; $(\mathrm{c}, \mathrm{d})$ at $132{ }^{\circ} \mathrm{C}$; $(\mathrm{e}-\mathrm{h})$ at $147^{\circ} \mathrm{C}$. 
(a)

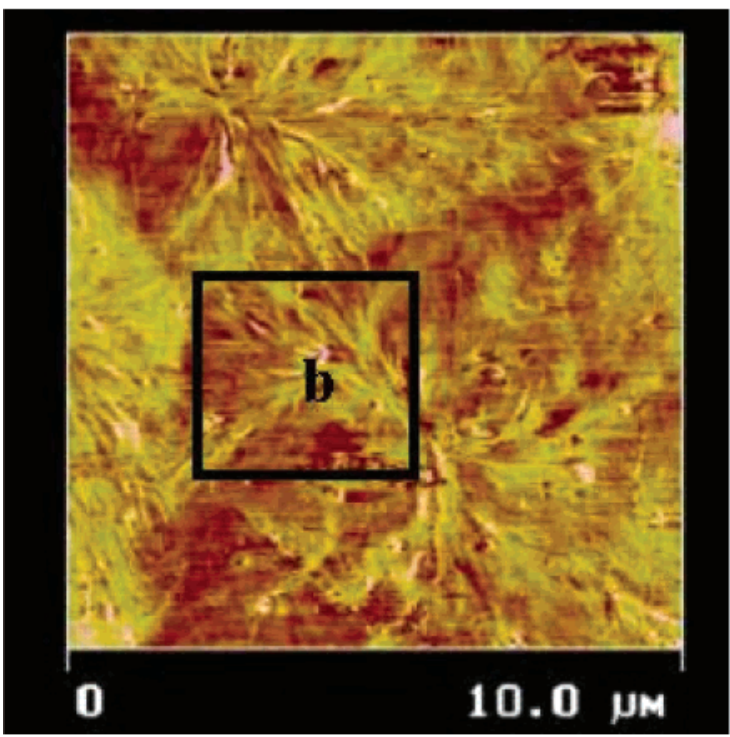

(c)

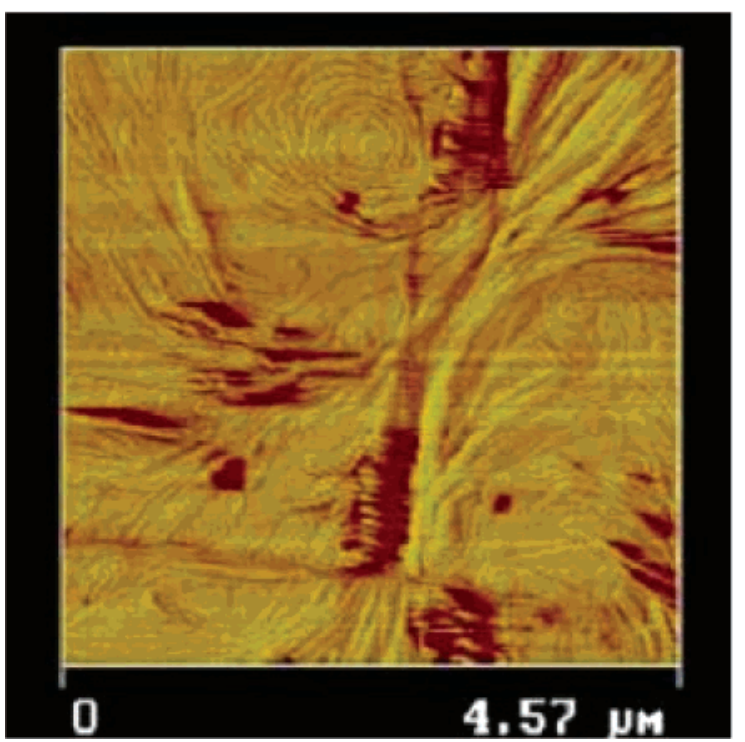

(b)

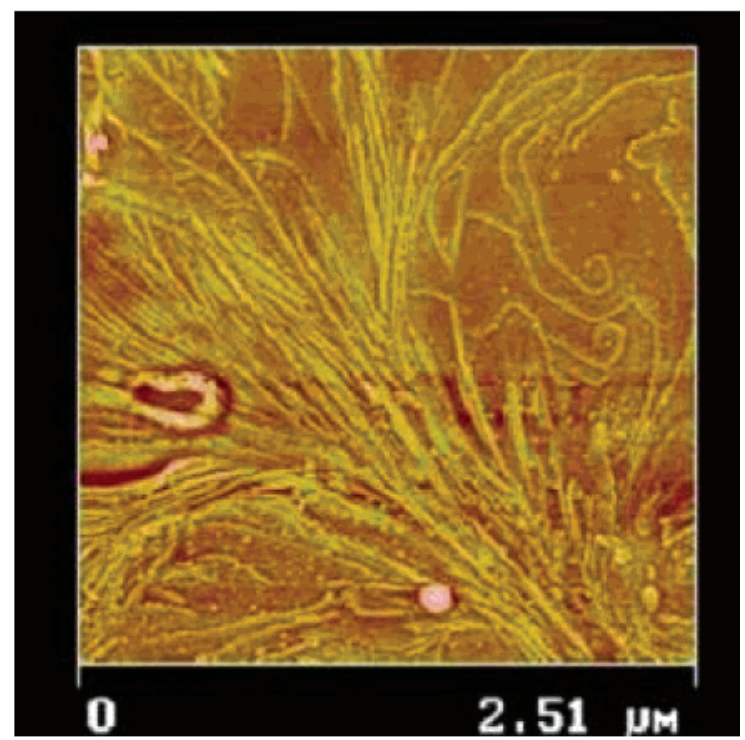

(d)

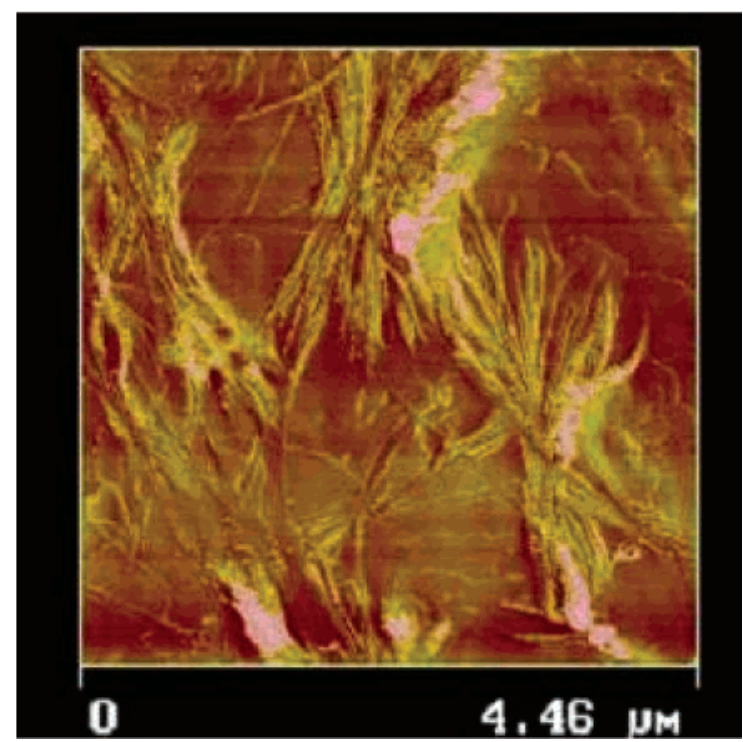

Figure 2. Phase images of $6 \%$ meso-lactide copolymer crystallized at different temperatures: $(a, b)$ at $114{ }^{\circ} \mathrm{C} ;(\mathrm{c}, \mathrm{d})$ at $120{ }^{\circ} \mathrm{C}$.

left portion. Lamellar sheaflike structures such as those seen in Figure $1 b$ are generally considered to be an intermediate stage in the development of a 3D spherulitic superstructure. The structure consists of organized, interconnected lamellae. Planar lamellae (an example of which is indicated with arrow A in Figure 1b) are typically observed in central portions of the superstructures. These "dominant" lamellae are seen to splay (an example of which is indicated by arrow B in Figure 1b) and branch (see arrow $C$ in Figure 1b) at later stages of growth. It has been proposed that the splaying results from repulsive forces between lamellae, possibly originating from cilia or uncrystallized segments protruding from fold surfaces. ${ }^{23,24}$

As seen in Figure 1, the mean size of the PLLA superstructure at $120{ }^{\circ} \mathrm{C}$ is smaller than that crystallized at higher $T_{\mathrm{c}}$ 's, that is, at 132 and $147^{\circ} \mathrm{C}$. This is also true for the $3 \%$ and $6 \%$ meso-lactide copolymers (not shown) and is in good agreement with previous work in which primary nucleation density was found to decrease at lower $\Delta T .^{9}$
Compact spherulitic structures are observed on the surface of PLLA crystallized at $120^{\circ} \mathrm{C}$, while more open structures are seen in PLLA crystallized at higher $T_{\mathrm{c}}$. For example, Figure 1c shows an image of a portion of a PLLA spherulite crystallized at $132{ }^{\circ} \mathrm{C}$. Comparison between the highmagnification images of PLLA crystallized at $120^{\circ} \mathrm{C}$ (Figure 1b) and at $132{ }^{\circ} \mathrm{C}$ (Figure 1d) shows lamellae to be packed more closely in the former. Regions between edge-on lamellar stacks filled with spiral terraces (flat on), indicative of screw dislocations, are seen in Figure 1c, and one such region is marked with an arrow. Screw dislocations are one of the factors that lead to space filling in spherulites. ${ }^{25}$ At higher $T_{\mathrm{c}}$, the edge-on lamellae appear to be more separated (Figure 1f). Larger numbers of screw dislocations are observed between edge-on lamellae, as well as in regions far from the center of spherulites (Figure 1h). Lamellar orientation on the surface of PLLA crystallized at $147^{\circ} \mathrm{C}$ is different from those crystallized at the lower $T_{\mathrm{c}}$ 's: they are mostly parallel to the surface. 
(a)

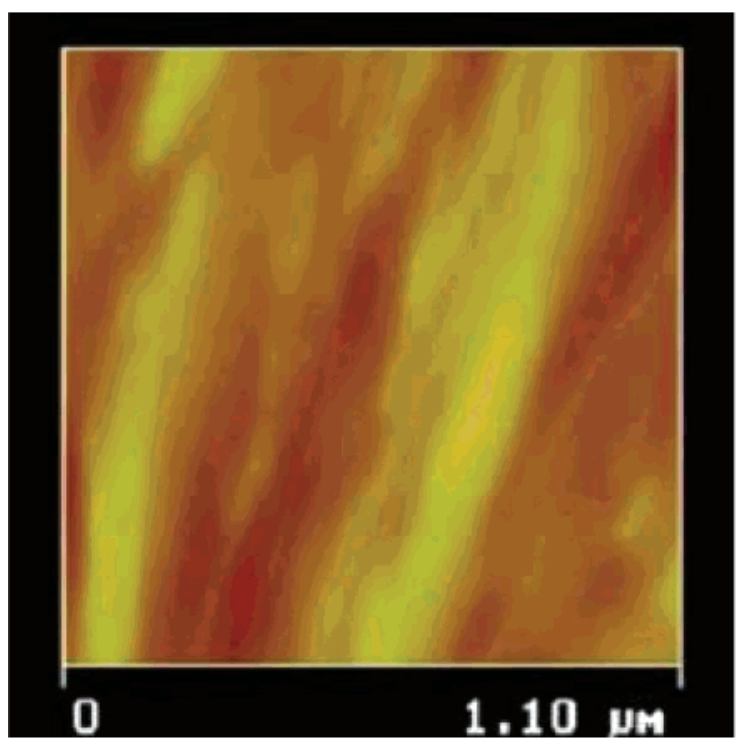

(c)

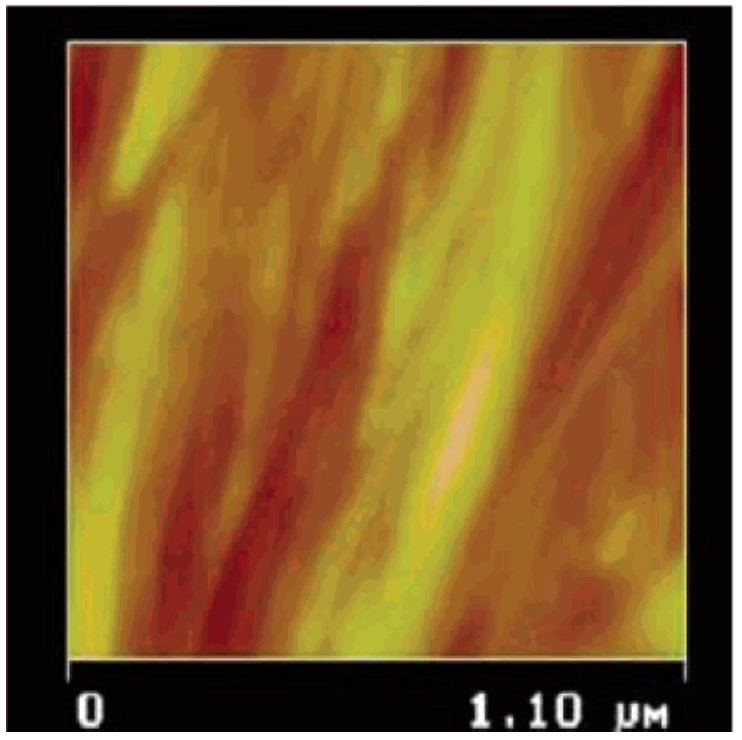

(b)

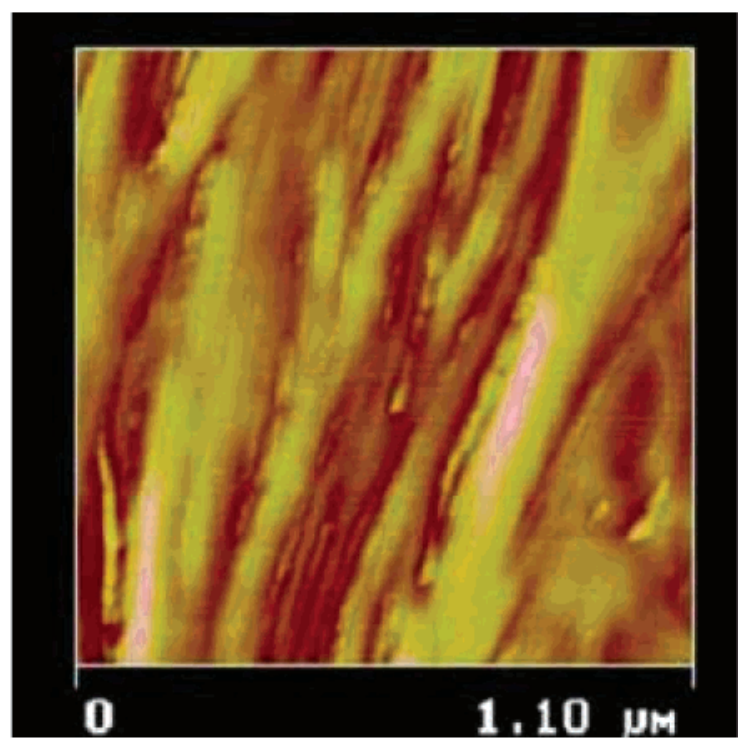

(d)

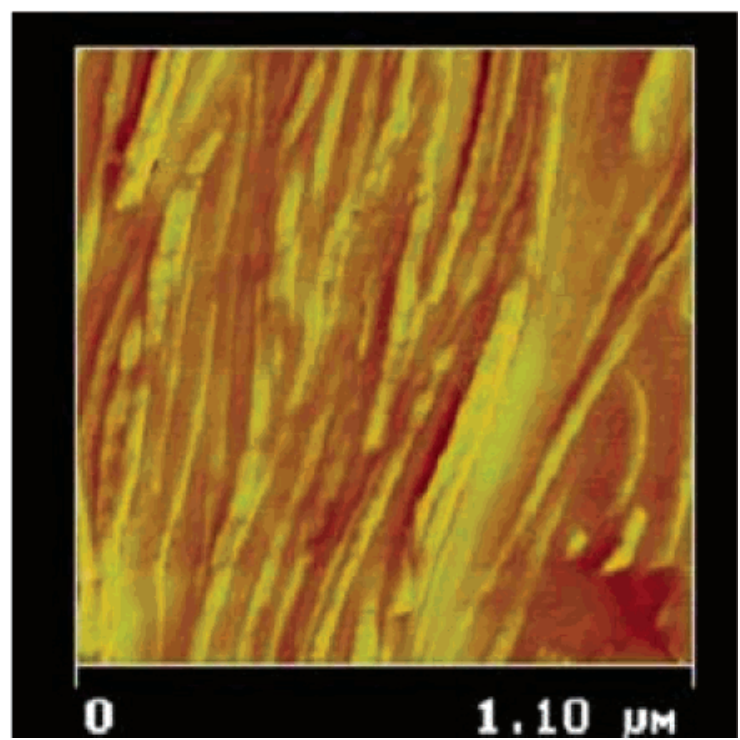

Figure 3. Height $(\mathrm{a}, \mathrm{c})$ and phase $(\mathrm{b}, \mathrm{d})$ images of PLLA crystallized at $126{ }^{\circ} \mathrm{C}$ at a set-point amplitude ratio of $(\mathrm{a}, \mathrm{b}) r_{\mathrm{sp}} \approx 0.78$ and $(\mathrm{c}, \mathrm{d}) r_{\mathrm{sp}} \approx$ 0.69 .

High-magnification images of different regions of the $6 \%$ meso-lactide copolymer crystallized at $120^{\circ} \mathrm{C}$ are shown in Figure 2c,d. Figure 2c shows a view of the central portion of a spherulite. Many areas in Figure $2 d$ exhibit edge-on lamellae, oriented mostly parallel to each other within sheaflike structures. Note also the absence of branch points for edge-on lamellae. Sheaflike structures with more complex lamellar organization are observed for PLLA crystallized at the same $T_{\mathrm{c}}$ (Figure 1a,b). A comparison of Figures $1 \mathrm{~b}$ and $2 \mathrm{~d}$ suggests that increasing comonomer content leads to a reduction in the average number of lamellae per stack. The effect of crystallization temperature on crystalline microstructure of the $3 \%$ and $6 \%$ meso-lactide copolymers is similar to that observed for PLLA.

B. Contrast in Height and Phase Images. Tapping force, as influenced by $A_{0}$ and $r_{\mathrm{sp}}$, is an important experimental variable and its effect on features observed in AFM height and phase images has been discussed in a number of publications. ${ }^{17,26-30}$ Low force (i.e., high $r_{\mathrm{sp}}$ with moderate $A_{0}$ ) is normally desirable for obtaining true surface topography; tip-sample surface interactions are weak in this case. At higher tapping forces (i.e., lower $r_{\mathrm{sp}}$ and moderate/large $A_{0}$ ), the image is influenced by the strong tip-sample interactions and the indentation force is dominated by sample stiffness and tip-sample contact area. For heterogeneous surfaces (e.g., those consisting of crystalline and amorphous regions), contrast is often improved at higher tapping forces. ${ }^{28}$ Larger tapping forces are also necessary for probing a component lying beneath a surface. ${ }^{26}$ However, higher forces can result in surface indention and distortion (broadening) of the apparent lateral dimensions of features. In the current work, an important objective is to quantitatively determine lamellar thickness as a function of crystallization conditions and comonomer content. Therefore, experiments were initially conducted at low tapping force. If the results from a given low-force experiment were deemed unsatisfactory for 


\section{(a) Height image}
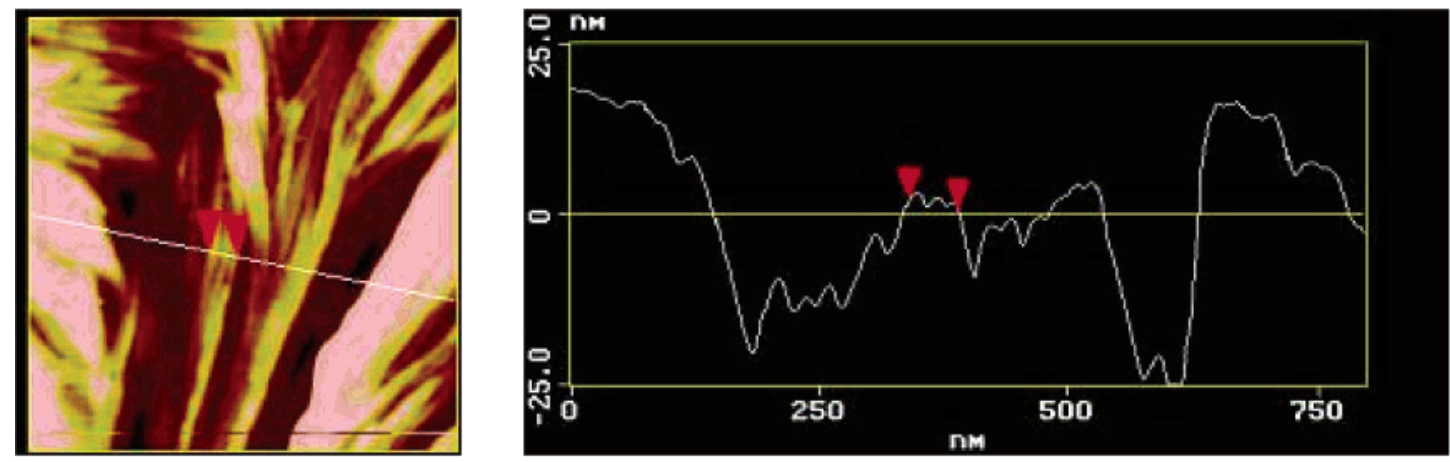

\section{(b) Phase image}
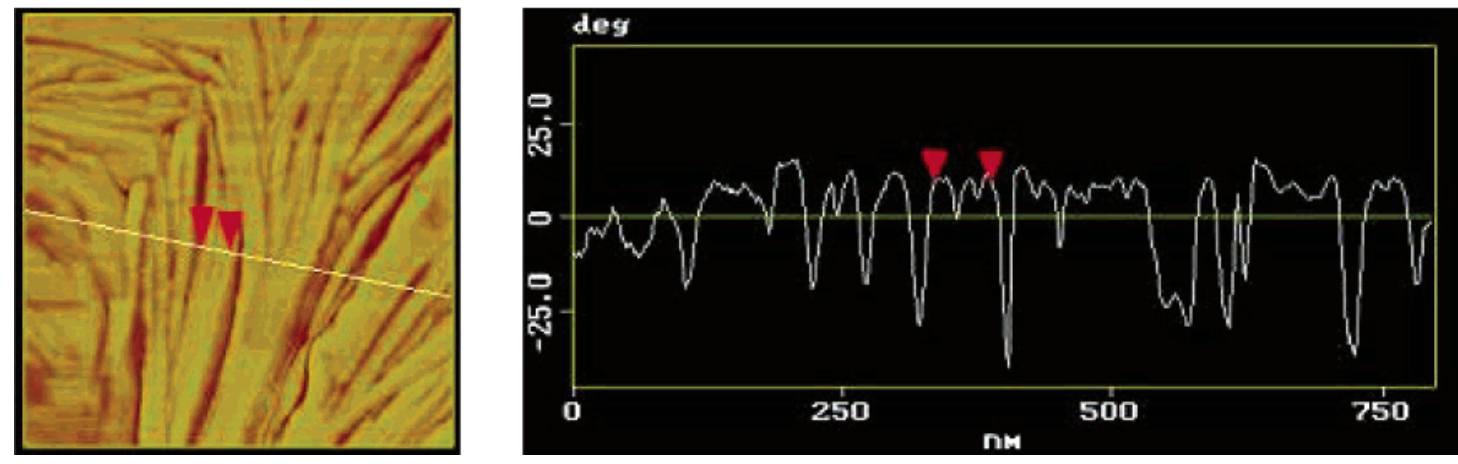

Figure 4. PLLA crystallized at $120^{\circ} \mathrm{C}$ : (a) height image and sectional profile; (b) phase image and sectional profile.

quantitative analysis, one or more higher-tapping-force experiments were performed.

Height images are obtained at constant amplitude, where the cantilever tip height is controlled via a feedback routine so as to maintain a constant set-point amplitude (and thus a constant average normal force). Therefore, information in height images, taken at moderate $A_{0}$ and moderate/low $r_{\mathrm{sp}}$, is related to sample topography and stiffness. Phase images are obtained concurrently with height images by monitoring the phase lag between the oscillating tip (output) and the driving signal of the piezo element (input). The contrast in this imaging mode is dramatically modified by tip-sample interactions (attractive forces (adhesion) and repulsive forces (indentation) at higher and lower $r_{\mathrm{sp}}$, respectively). The polylactides under investigation all have glass-transition temperatures $T_{\mathrm{g}} \approx 60{ }^{\circ} \mathrm{C}$ (see Table 1 ), significantly above ambient. There is a difference in stiffness between the glassy amorphous and crystalline regions, and although not large, it is sufficient for contrast development. Contrast modification with varying tapping force is exhibited in Figure $3 a-d$. The images in Figure 3 were acquired from the same area of a PLLA specimen crystallized at $126{ }^{\circ} \mathrm{C}$ but at two different $r_{\mathrm{sp}}$. Increasing tapping force remarkably improves the contrast between the crystalline and amorphous regions in the phase images, but there is little change in the corresponding height images. As a result, this indicates that the features observed in height images at these scanning conditions are dominated by the surface topography, while the phase images are determined by the indentation forces.

C. Determination of Lamellar Thicknesses. Methodology. Given the excellent spatial resolution achievable with tapping mode AFM, the question of using this technique for quantitative analysis of domain sizes has naturally arisen. Three important factors influence AFM spatial resolution: scan size,$^{31}$ the effect of tip geometry, and sample deformation. ${ }^{30,32,33}$ Analyses in our work were performed on images with dimensions between $0.8 \times 0.8$ and $1.2 \times 1.2 \mu \mathrm{m}^{2}$ to rule out the influence of scan size on determining feature widths on the order of $10 \mathrm{~nm}$ (500 pixels provide sufficient resolution). Only a few images with large dimensions, that is, $\sim 1.6 \times 1.6 \mu \mathrm{m}^{2}$, were taken into the consideration. As seen in the previous section, lamellar orientation varies from area to area. A relatively wide area was imaged first to view a region covered with sheaflike structures. Subsequently, regions with a comparatively high concentration of planar edge-on lamellae, for example, near a center of the sheaflike structure, were chosen and imaged at higher magnifications. Samples were characterized initially at low tapping force to avoid surface deformation, but sufficient contrast could not always be obtained under such conditions, requiring the use of somewhat higher tapping forces.

The widths of edge-on lamellae from height or phase images (perpendicular to the long axes of the lamellae) were determined using the "section analysis" portion of the Nanoscope AFM software. Because the possibility of some small inclination of lamellae to the surface cannot be ruled out, the mean lamellar thicknesses $\left(l_{c}\right)$ and their distributions should strictly be considered "apparent" ${ }^{16}$ Only height images of PLLA samples crystallized at $120^{\circ} \mathrm{C}$ (largest $\Delta T$ ) exhibit contrast as good as that observed in phase images, as demonstrated in Figure 4. There are however a modest 


\section{(a) Height image}
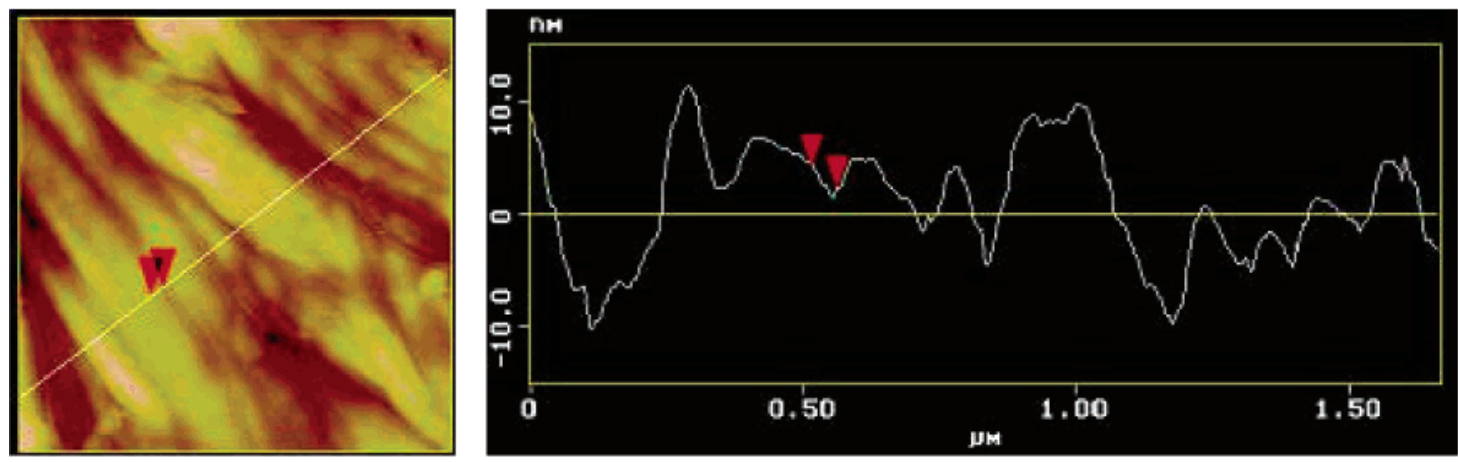

\section{(b) Phase image}
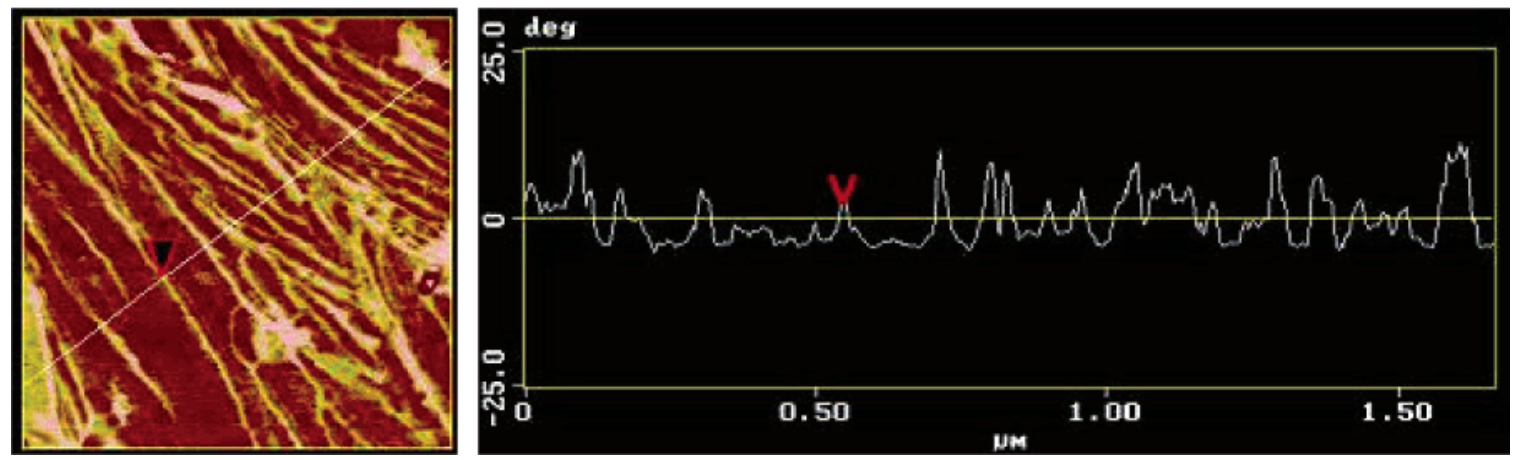

Figure 5. meso-Lactide (3\%) copolymer crystallized at $114^{\circ} \mathrm{C}$ : (a) height image and sectional profile; (b) phase image and sectional profile.

number of other samples for which the height images exhibit sufficient contrast so that quantitative analysis could be conducted.

As seen in Figures 3-5, it is clear that crystalline lamellae are associated with brighter regions in the phase images, as expected for the set points $\left(r_{\mathrm{sp}}\right)$ used..$^{28,30,34}$ Brighter regions in height images however can be either crystalline lamellae or amorphous regions, but this assignment can be made by reference to the corresponding phase image. For the 3\% meso-lactide copolymer (Figure 5), the lamellar structure is clearly observed only in the phase image (Figure 5b); thus, we conclude that the surface of the copolymer specimens are covered with uncrystallized melt. This obviously creates problems in determining lamellar thicknesses from these height images. For example, it is not possible to delineate the lamellar structure of the $3 \%$ copolymer (crystallized at $114^{\circ} \mathrm{C}$ ) in the marked area of the height image (Figure 5a). However, the phase image of the same region clearly shows the lamellar morphology (Figure 5b). This permits characterization of the microstructure without having to stain, etch, or otherwise modify the polymers to reveal the crystalline regions lying beneath the surface.

The tip geometry of the silicon probe can have a significant influence on the image acquired. Analysis of selected AFM tips used in our experiments by scanning electron microscopy (see description in the Supporting Information) shows that the tips are cone-shaped with $\theta=15^{\circ}$ and $\theta^{\prime}=19^{\circ}$. To determine the thickness of edge-on lamellae, deconvolution of the tip profile was taken into consideration as also demonstrated in the Supporting Information. The apparent lamellar thickness was found to be overestimated by $\sim 0.4-1$ $\mathrm{nm}$, which constitutes a correction of only $\sim 3-10 \%$ in the measured value.

Quantitative interpretation of data from phase images must be done carefully, particularly because some details of phase image formation are not completely understood. ${ }^{28,30,34} \mathrm{Nev}$ ertheless, it is possible to determine feature sizes from phase images (e.g., refs 16 and 35), although there is an uncorrected effect of the tip profile on the image (presumably relatively small) along with uncertainties due to broadening from high normal force and from the possibility of lamellar tilt. Lamellar thicknesses were estimated from phase images using the width at half-height of well-defined peaks in section profiles of edge-on lamellae (Figure $5 b$ ).

PLLA. Figure 6 shows a plot of the mean lamellar thicknesses as a function of crystallization temperature for PLLA, determined from AFM height (where possible) and phase images. These values are also tabulated in Table 2, along with the corresponding $95 \%$ confidence intervals around the means. Fewer lamellae in height images can be confidently used for quantitative analysis, as seen in the last column of Table 2. This results from the contrast limitation in height images noted above. Also displayed in Figure 6 are values determined in our previous SAXS study of the identical PLLA and copolymers. ${ }^{9}$ The SAXS values were determined from a "finite" lamellar stack model (the principle evidence for this is the relationship between the bulk and linear crystallinities). Note that the AFM and SAXS values are quite similar considering the experimental error, confirming the scattering model used in the interpretation of the SAXS data. In addition, these results indicate that lamellar thicknesses extracted from surfaces of films by AFM are 


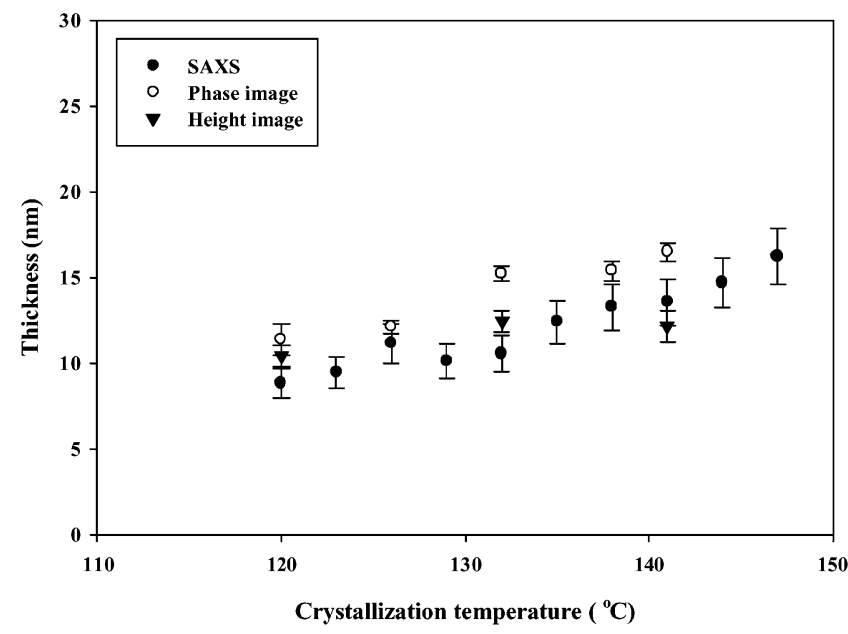

Figure 6. Mean thickness of PLLA lamellae determined from AFM height and phase imaging, as well as that reported previously from SAXS, ${ }^{9}$ as a function of $T_{\mathrm{c}}$. The error bars for the AFM data represent $95 \%$ confidence limits for the mean values. The error bars on the SAXS data represent $\pm 10 \%$ uncertainty.

Table 2. Mean Lamellar Thickness and Distribution from AFM Phase and Height Images

\begin{tabular}{|c|c|c|c|c|}
\hline \multicolumn{2}{|c|}{ sample } & \multirow[b]{2}{*}{$\begin{array}{c}\text { mean } \\
(\mathrm{nm})\end{array}$} & \multirow[b]{2}{*}{$\begin{array}{c}95 \% \text { confidence } \\
\text { interval }( \pm)\end{array}$} & \multirow[b]{2}{*}{$\begin{array}{c}\text { number of } \\
\text { lamellae }\end{array}$} \\
\hline material & $\begin{array}{c}T_{\mathrm{c}} \\
\left({ }^{\circ} \mathrm{C}\right) \\
\end{array}$ & & & \\
\hline \multicolumn{5}{|c|}{ Phase Image } \\
\hline \multirow[t]{5}{*}{ PLLA } & 120 & 11.4 & 0.9 & 58 \\
\hline & 126 & 12.1 & 0.4 & 158 \\
\hline & 132 & 15.2 & 0.4 & 182 \\
\hline & 138 & 15.4 & 0.6 & 84 \\
\hline & 141 & 16.5 & 0.5 & 210 \\
\hline \multirow[t]{5}{*}{$3 \%-m e s o$} & 114 & 12.4 & 1.0 & 56 \\
\hline & 120 & 12.2 & 1.4 & 45 \\
\hline & 126 & 13.5 & 0.4 & 143 \\
\hline & 132 & 11.9 & 0.8 & 58 \\
\hline & 135 & 13.3 & 0.5 & 185 \\
\hline \multirow[t]{4}{*}{$6 \%$-meso } & 114 & 11 & 0.6 & 109 \\
\hline & 117 & 9.5 & 0.6 & 55 \\
\hline & 120 & 9.7 & 0.8 & 52 \\
\hline & 126 & 9.9 & 0.7 & 57 \\
\hline \multicolumn{5}{|c|}{ Height Image } \\
\hline \multirow[t]{3}{*}{ PLLA } & 120 & 10.4 & 0.6 & 39 \\
\hline & 132 & 12.4 & 0.7 & 73 \\
\hline & 141 & 12.2 & 0.9 & 49 \\
\hline \multirow[t]{2}{*}{ 3\%-meso } & 126 & 11.3 & 0.6 & 59 \\
\hline & 135 & 11.2 & 0.7 & 60 \\
\hline $6 \%-m e s o$ & 114 & 10.5 & 0.9 & 24 \\
\hline
\end{tabular}

representative, at least in this case, of the mean bulk $l_{\mathrm{c}}$ as determined by SAXS.

In the work of Abe et al., 18 "lamellar periodicities" estimated from profiles of flat-on PLLA lamellae crystallized at 120 and $140{ }^{\circ} \mathrm{C}$ are in the range of $14-16$ and $16-18$ $\mathrm{nm}$, respectively. These values are approximately $2-5 \mathrm{~nm}$ larger than the lamellar thicknesses determined here. However, this would be expected because both the crystalline and amorphous layers are measured for the flat-on lamellae. Even though the experiments in ref 18 and in the current paper were performed using different AFM methods (i.e., dynamic force vs tapping mode), there is consistency in the results of these two studies.

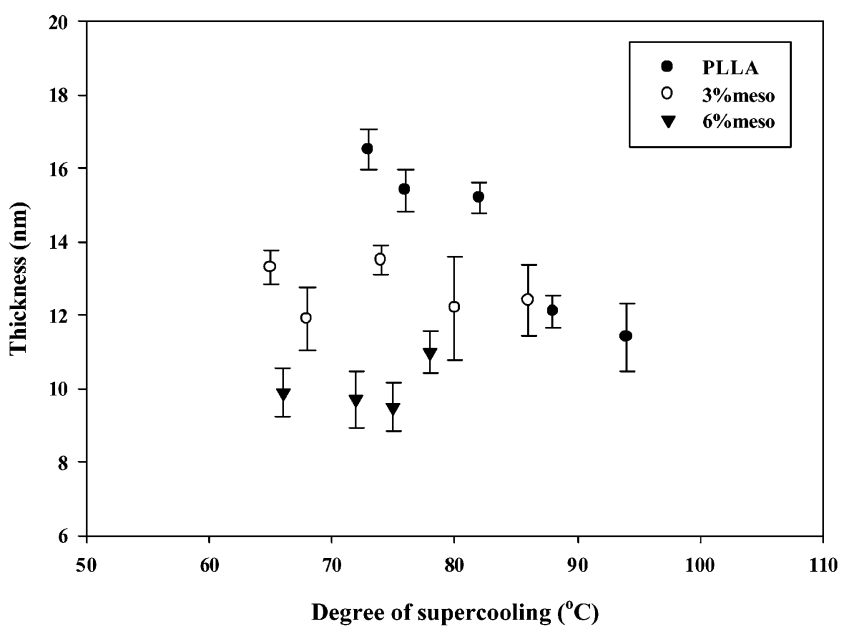

Figure 7. Mean lamellar thicknesses for PLLA and 3\% and 6\% mesolactide copolymers as a function of degree of supercooling from AFM phase images. The error bars represent the $95 \%$ confidence limits of these mean values.

meso-Lactide Copolymers. As expected (see Table 2 and Figure 6), mean lamellar thicknesses increase with increasing $T_{\mathrm{c}}$ for PLLA (from $\sim 11$ to $17 \mathrm{~nm}$ from phase images). In general, however, the influence of $T_{\mathrm{c}}$ on the crystal thickness of the copolymers (3\% and $6 \%$ meso) is difficult to distinguish because of the experimental uncertainty associated with individual data points. However, lamellar thicknesses for the copolymers are generally smaller than those for PLLA, particularly at lower $\Delta T$, in agreement with results from our previous SAXS experiments. As discussed earlier, such a reduction with comonomer content is consistent with substantial $R$ stereoisomer exclusion from crystalline regions. Mean $l_{\mathrm{c}}$ values derived from phase images are shown in Figure 7. Thickness distributions for all samples from height and phase images are presented in Figure 8. Lamellar thicknesses from phase images are consistently higher than those from height images (although within experimental uncertainty for some samples). In addition, the thickness distributions from phase images tend to be skewed somewhat to larger sizes (note that the size scale changes from panel $\mathrm{a}$ to panel $\mathrm{b}$ and from panel $\mathrm{c}$ to panel $\mathrm{d}$ of Figure 8). There are several possible reasons for this. As noted earlier, the contrast in phase images is formed from complex tip-sample interactions, and the influence of the tip profile on these images is uncorrected. In addition, to define lamellar thicknesses reasonably, slightly different procedures were used for height (width of constant height region, Figure 4a) vs phase images (width at half-height of well-defined peaks in section profiles, Figures $4 \mathrm{~b}$ and $5 \mathrm{~b}$ ). In the present analysis, lamellae distinguishable in height images represent only $\sim 20-50 \%$ of the population resolvable in the phase image of the same spatial region that was analyzed. This difference in sampling could also contribute to differences in mean thickness values and distributions determined from height and phase images.

D. Bulk Morphology. As an extension of the work described in the previous sections, the bulk morphology was investigated by evaluating "microtomed" samples, that is, internal surfaces of the samples were exposed by microtoming away the outer parts of specimens and subsequently 
(a)

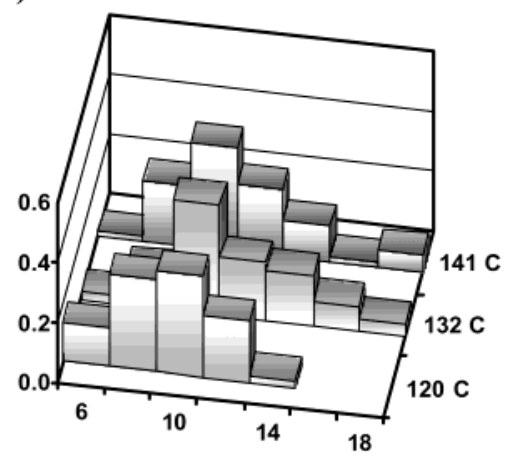

(c)

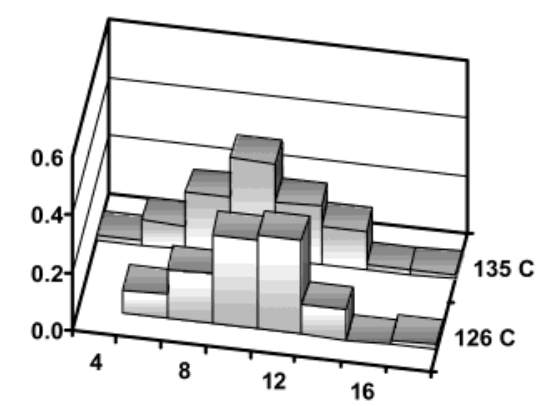

(e)

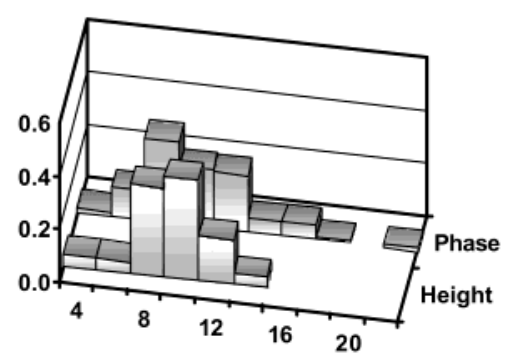

(b)

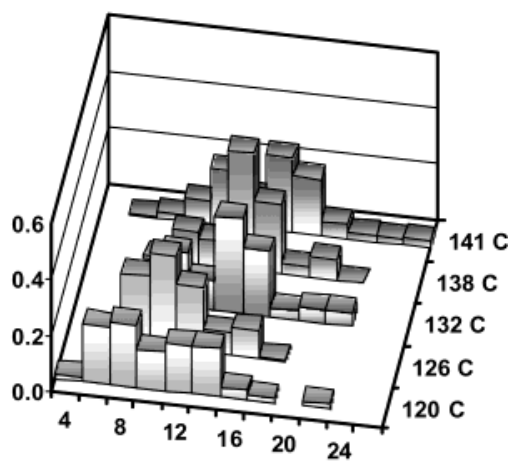

(d)

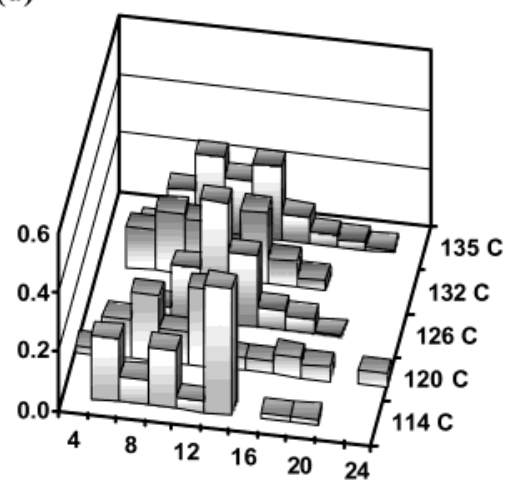

(f)

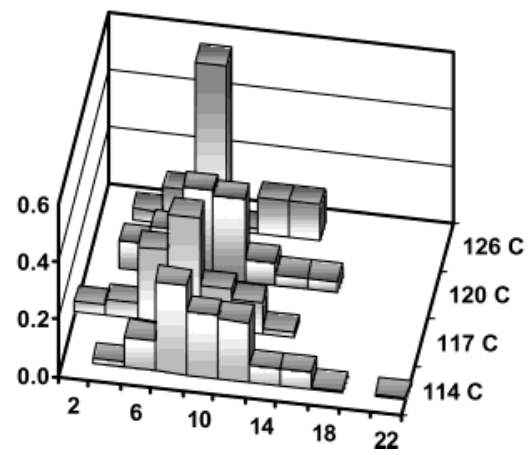

Figure 8. Lamellar thickness distributions of (a,b) PLLA, (c,d) $3 \%$ meso-lactide copolymer, and (e,f) $6 \%$ meso-lactide copolymer as a function of $T_{\mathrm{c}}$. Data in panels a and c determined from height images, in panels $\mathrm{b}, \mathrm{d}$, and f from phase images, and in panel e from both height and phase images of the $6 \%$ meso-lactide copolymer crystallized at $114{ }^{\circ} \mathrm{C}$. The $x$-axis represents thickness $(\mathrm{nm})$, the $y$-axis represents $T_{\mathrm{c}}$ or imaging mode, and the $z$-axis represents the fraction of lamellar thickness distribution.

imaged by AFM. Knife marks are clearly visible in AFM images (not shown) of samples microtomed at room temperature $\left(\sim 40^{\circ} \mathrm{C}\right.$ below $\left.T_{\mathrm{g}}\right)$, inhibiting evaluation of the bulk microstructure. Microtoming at lower temperature $\left(-25^{\circ} \mathrm{C}\right)$ produced specimens with much smoother surfaces. As an example of our findings, Figure 9 presents height and phase images of a cross section of PLLA crystallized at $132{ }^{\circ} \mathrm{C}$. Spherulites are revealed in low-magnification images (see Figure 9a, for example). Areas marked as B and C were probed at higher magnification (Figure 9b,c) in an attempt to obtain information on the lamellar subunits. Lamellae similar to those seen in the "free" surface experiments are observed, as seen in higher magnification images such as Figure 9c,d, albeit with reduced clarity compared to the ones obtained at the "free" surface. The qualitative similarity between these lamellae and the ones observed at the polymer surface, combined with the quantitative agreement of the lamellae thickness as measured by AFM at the surface and by SAXS in the bulk, strongly suggests that the morphologies observed at the polymer surface closely reflect the bulk crystal morphology of these polymers.

Lamellar organization in spherulitic superstructures is complex, lamellae being oriented randomly in three dimensions and disordered regions intervening. Considering that sectioning through this structure occurs randomly, as does selection of an area for scanning, the probability of observing a large number of edge-on lamellae for thickness measurement is low. Moreover, surface roughness, even when microtoming at $-25^{\circ} \mathrm{C}$, leads to a reduction in resolution. As a consequence, our images of cross sections are not suitable for quantitative analysis of lamellar thickness.

\section{Summary}

High-resolution tapping mode AFM provides a promising way of performing qualitative and quantitative studies of 
(a)

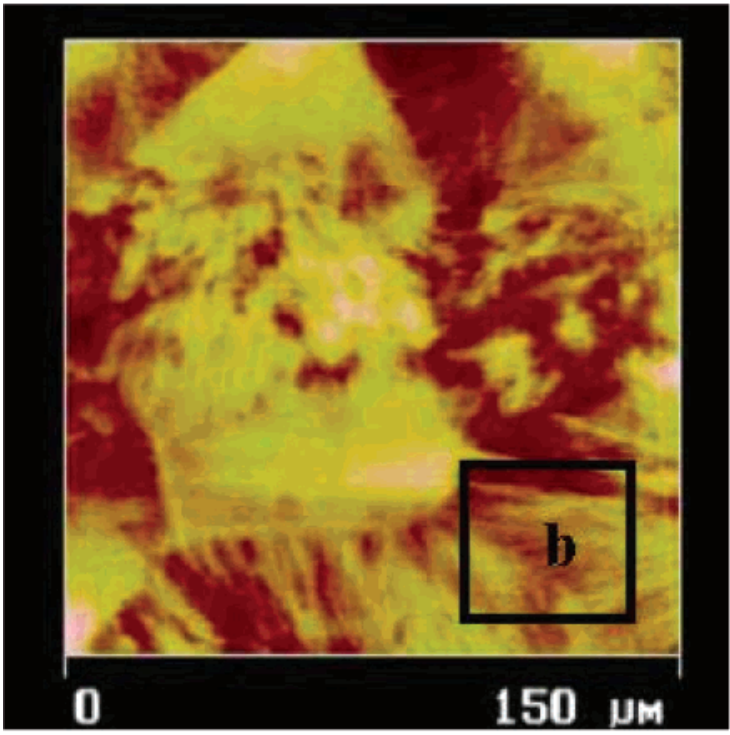

(c)

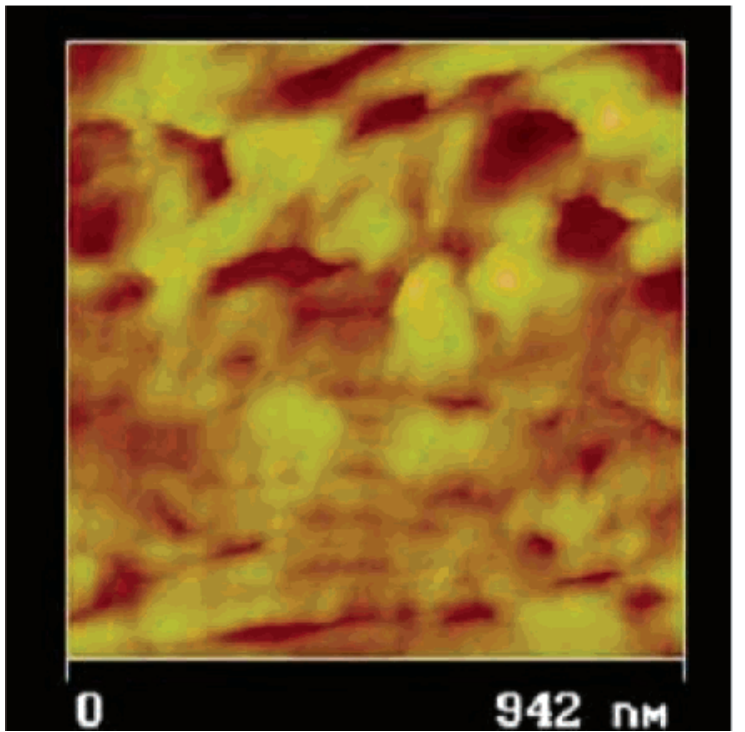

(b)

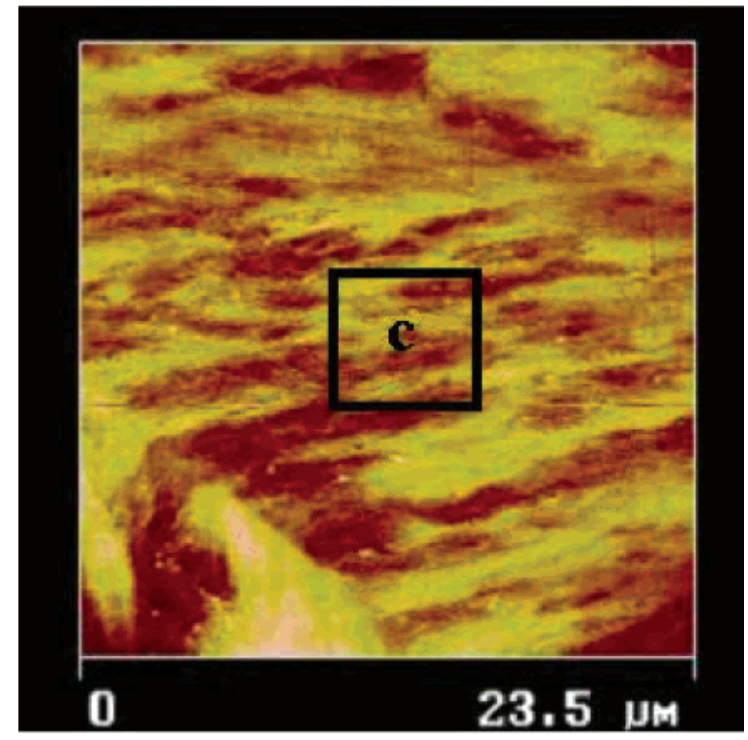

(d)

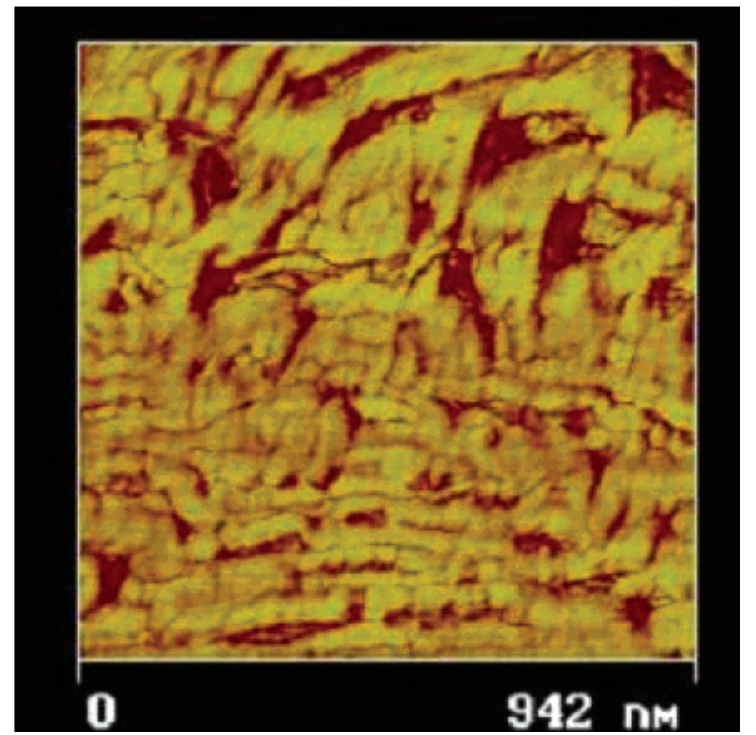

Figure 9. Height images $(\mathrm{a}-\mathrm{C})$ of PLLA $\left(T_{\mathrm{c}}=132^{\circ} \mathrm{C}\right)$ microtomed at $-25^{\circ} \mathrm{C}$ and phase image (d) of the same area as that in panel $\mathrm{C}$.

lamellar microstructure of crystalline polymers without the requirement of complex sample preparation methods. In the current study, we investigate the lamellar morphology of PLLA and two poly(L-lactide-co-meso-lactide) random copolymers. Mean lamellar thicknesses are lower for the random copolymers compared to PLLA, particularly at lower $\Delta T$. Along with the fact that the degree of crystallinity decreases by about a factor of 2 upon introducing $\sim 3 \%$ randomly placed $R$ counits, ${ }^{9}$ this result strongly suggests that a significant portion of the $R$ stereounits are rejected from crystalline lamellae. The most important finding of the present study is that lamellar thicknesses determined from AFM phase and height images are in good agreement with those determined in our previous SAXS study of the identical materials.

Acknowledgment. The authors express their appreciation to the donors of the ACS Petroleum Research Fund and the
National Science Foundation (Grant DMR-0211056) for their support of this work. AFM instrumentation was supported through NSF (Grant DMR-9975624). We also thank Dr. Vasileios Koutsos (University of Edinburgh) for a number of very helpful discussions. Finally, we thank Mr. Eric Hall at Cargill Dow for providing the polymers used in this study and colleagues at Cargill Dow for determining molecular weights and performing chiral chromatography analysis.

Supporting Information Available. Figure showing the tip geometry and illustrating the effect of tip convolution. This material is available free of charge via the Internet at http://pubs.acs.org.

\section{References and Notes}

(1) Makino, K.; Arakawa, M.; Kondo, T. Chem. Pharm. Bull. 1985, 33, 1195.

(2) Reeve, M.; McCarthy, S.; Downey, M.; Gross, R. Macromolecules 1994, 27, 825 . 
(3) MacDonald, R.; McCarthy, S.; Gross, R. Macromolecules 1996, 29, 7356.

(4) Tsuji, H.; Ikada, Y. Polymer 1995, 36, 2709.

(5) Iannace, S.; Maffezzoli, A.; Leo, G.; Nicolais, L. Polymer 2001, 42, 3799.

(6) Pluta, M.; Galeski, A. J. Appl. Polym. Sci. 2002, 86, 1386.

(7) Tsuji, H.; Ikada, Y. Macromol. Chem. Phys. 1996, 197, 3483.

(8) Sarasua, J. R.; Prud'homme, R. E.; Wisniewski, M.; Borgne, A. L.; Spassky, N. Macromolecules 1998, 31, 3895.

(9) Huang, J.; Lisowski, M. S.; Runt, J.; Hall, E. S.; Kean, R. T.; Buehler, N.; Lin J. S. Macromolecules 1998, 31, 2593.

(10) Baratian, S.; Hall, E. S.; Lin, J. S.; Xu, R.; Runt, J. Macromolecules 2001, 34, 4857

(11) Tsuji, H.; Ikada, Y. Macromolecules 1992, 25, 5719.

(12) Brochu, S.; Prud'homme, R. E.; Barakat, I.; Jerome, R. Macromolecules 1995, 28, 5230.

(13) Cho, J.; Baratian, S.; Kim, J.; Yeh, F.; Hsiao, B. S.; Runt, J. Polymer 2003, 44, 711 .

(14) Sanchez, I. C.; Eby, R. K. Macromolecules 1975, 8, 638.

(15) Trifonova, D.; Varga, J.; Vancso, G. J. Polym. Bull. 1998, 41, 341.

(16) Ivanov, D.; Amolou, Z.; Magonov, S. Macromolecules 2001, 34, 8944.

(17) Schonherr, H.; Bailey, L. E.; Frank, C. W. Langmuir 2002, 18, 490.

(18) Abe, H.; Kikkawa, Y.; Inoue, Y.; Doi, Y. Biomacromolecules 2001, 2, 1007.

(19) Kikkawa, Y.; Abe, H.; Iwata, T.; Inoue, Y.; Doi, Y. Biomacromolecules 2002, 3, 350.

(20) Cicero, J. A.; Dorgan, J. R. J. Polym. Environ. 2002, 9, 1.

(21) Kanchanasopa, M.; Manias, E.; Runt, J. ACS Polym. Prepr. 2001, $42(2), 300$
(22) Thakur, K. A. M.; Kean, R. T.; Hall, E. S.; Kolstad, J. J.; Lindgren, T. A.; Doscotch, M. A.; Siepmann, J. I.; Munson, E. J. Macromolecules 1997, 30, 2422

(23) Bassett, D. C.; Olley, R. Polymer 1984, 25, 935.

(24) Bassett, D. C.; Vaughen, A. S. Polymer 1985, 26, 717.

(25) Bassett, D.; Hodge, A. Proc. R. Soc. London 1981, A377, 61.

(26) Magonov, S. N.; Cleveland, J.; Elings, V.; Denley, D.; Whangbo, M. H. Surf. Sci. 1997, 389, 201.

(27) Van Noort, J. T.; Van der Werf, K. O.; De Grooth, B. G.; Van Hulst, N. F. Ultramicroscopy 1997, 69, 117.

(28) Bar, G.; Thomann, Y.; Brandsch, R.; Cantow, H. J. Whangbo, M. H. Langmuir 1997, 13, 3807.

(29) Pickering, J. P.; Vancso, G. J. Polym. Bull. 1998, 40, 549.

(30) Knoll, A.; Magerle, R.; Krausch, G. Macromolecules 2001, 34, 4159.

(31) Scan size affects the image resolution because by design the instrument collects 512 points $\times 512$ points for each scanned image; thus, each "pixel"/point in a $10 \mu \mathrm{m}$ scan corresponds to a $19.5 \times$ $19.5 \mathrm{~nm}^{2}$ sample area, and for a $1.6 \mu \mathrm{m}$ scan line, each point corresponds to about $3 \mathrm{~nm}$.

(32) Sheyko, S. Adv. Polym. Sci. 2000, 151, 61.

(33) Weihs, T.; Nawaz, Z.; Jarvis, S.; Pethica, J. Appl. Phys. Lett. 1991, 59,3536

(34) Schmitz, I.; Schreiner, M.; Friedbacher, G.; Grasserbauer, M. Appl. Surf. Sci. 1997, 115, 190.

(35) Basire, C.; Ivanov, D. A. Phys. Rev. Lett. 2000, 85, 5587.

BM034063W 